\title{
Reducing and preventing alcohol misuse and its consequences: $A$ Grand Challenge for social work
}

\author{
Audrey L. Begun ${ }^{1}$, John D. Clapp ${ }^{1}$, and The Alcohol Misuse Grand Challenge Collective ${ }^{2}$ \\ ${ }^{1}$ College of Social Work, at The Ohio State University, Columbus, Ohio, United States \\ ${ }^{2}$ Listed in Appendix A
}

The paper, Reducing and Preventing Alcohol Misuse and Its Consequences: A Grand Challenge for Social Work, was originally published online (http://aaswsw.org/wp-content/uploads/2015/12/WP14-with-cover.pdf) as a Working Paper developed for the American Academy of Social Work and Social Welfare (AASWSW). The paper was written in response AASWSW's call for papers on Grand Challenges for Social Work. The goal of AASWSW's Grand Challenge initiative was to identify pressing social problems that had the potential to be greatly reduced over the next decade. The hope was to begin a dialogue that would transcend professional and national boundaries. The paper was written to stimulate development of a critical mass among those familiar with the alcohol arena, as well as to introduce the issues and possibilities to leaders and scholars in social work, from other professions/disciplines, and policy makers who do not work in the "alcohol field" per se.

As the readers of IJADR recognize, alcohol research and solutions to alcohol misuse are inherently multi-disciplinary. Although we often collaborate across disciplinary lines, individual scholars and our professional organizations are often isolated. The hope of re-printing this invited paper here is to facilitate its distribution and stimulate conversation between alcohol researchers and their peers studying other issues. We encourage you to share it with others. If you or your professional organization is interested in becoming involved in this Grand Challenge please contact, John D. Clapp at clapp.5@osu.edu.

\begin{abstract}
In both the United States and throughout the world, alcohol misuse is associated with high rates of morbidity, mortality, and cooccurring physical and mental health problems. It causes an array of acute and chronic problems and contributes to extensive costs in every sector of society (e.g., health, mental health, education, legal, economic productivity). The scientific discovery, development, and implementation of evidence-informed solutions for alleviating alcohol-related problems are inherently multisectoral, as they affect individuals, families, communities, and larger social systems. The advent of new technologies, research approaches, and intervention strategies has dramatically accelerated positive results in addressing such problems over the past 40 years. Still, alcohol misuse remains a significant global problem, and reducing and preventing its consequences is a Grand Challenge for Social Work. This paper addresses the following points about the challenge: (1) it is large, important, and compelling; (2) it can be analyzed and assessed; (3) demonstrable progress can be made in a decade; (4) multisectoral collaboration is required to meet this challenge; and (5) sustainable solutions to the challenge require significant, transformative, and groundbreaking innovations.
\end{abstract}

\section{Background}

Alcohol use is tightly woven into the fabric of human history and social life. Early historical references to alcohol-related problems date to 4000 BCE (Hanson, Venturelli, \& Fleckenstein, 2015; Howard, Garland, \& Whitt, 2013; McGovern, 2009; Singer, 2012). Alcohol use is integrated into celebrations, leisure, sport activities, entertainment, popular culture, and the global economy. Furthermore, alcohol can be beneficial to health and social situations when consumed in moderation. In appropriate contexts, it can reduce stress, enhance social connectedness, and reduce risk of certain medical conditions (e.g., cardiovascular disease, ischemic stroke, diabetes, disability, dementia, osteoporosis) (Gill, Shipley, Hornby, Gill, \& Beevers, 1988; Holbrook \& Barrett, 1993;
Karlamangla et al., 2009; Klatsky, 1999; Koppes et al., 2005; Neafsey \& Collins, 2011; Sampson, 2003).

Alcohol misuse involves drinking in greater quantities or more frequently than is advisable, and may involve drinking in risky situations or circumstances. Alcohol misuse is associated with high rates of morbidity, mortality, and co-occurring physical and mental health problems in the United States and globally. This paper addresses the consequences of alcohol misuse (i.e., deleterious effects on health and safety of individuals, families, and communities) and strategies for reducing and prevention them, making the following points about the challenge: (1) it is large, important, and compelling; (2) it can be analyzed and assessed; (3) demonstrable progress can be made in a decade; (4) multisectoral collaboration is required to meet

Correspondence: Audrey L. Begun, Ph.D., College of Social Work at The Ohio State University, Columbus, OH 43210, United States. Telephone: 614-292-1064; Email: begun.5@osu.edu;

Keywords: Alcohol, alcohol misuse, grand challenge, alcohol treatment, prevention, global, innovation and alcohol misuse, alcohol research 
this challenge; and (5) sustainable solutions to the challenge require significant, transformative, and groundbreaking innovations.

\section{The Challenge Is Large, Important, and Compelling}

Alcoholic beverages are by far the most commonly used and abused of psychoactive substances, and alcohol use has increased over the past decade (Dawson, Goldstein, Saha, \& Grant, 2015). According to the 2013 National Survey on Drug Use and Health (SAMHSA, 2014), more than 60 million individuals aged 12 years and older in the United States are estimated to have engaged in past-month binge drinking, and an estimated 16.5 million Americans have engaged in heavy drinking. By comparison, an estimated 24.6 million used illicit drugs or engaged in prescription drug abuse during the past month (SAMHSA, 2014). An estimated 21.6 million (8.2\%) of Americans aged 12 years and older experienced a diagnosable substance use disorder during the past year, and alcohol was involved for more than three-quarters of such individuals, either alone or in combination with other substances (SAMHSA, 2014). Considerable gaps exist between the 20.1 million individuals in the United States who need treatment for a substance use disorder and the estimated 2.5 million individuals who received care in a facility specializing in alcohol or other drug treatment (SAMHSA, 2014). Among those who did not receive the care for which they perceived a need, a lack of health coverage for specialized treatment was the most commonly cited barrier (SAMHSA, 2014). In the United States, nationwide cost estimates for 60 major illnesses places alcohol use disorders as the second and drug use disorders as the seventh most costly (Kirschstein, 2000); the cost of untreated alcohol misuse is estimated at $\$ 223.5$ billion annually (Research Society on Alcoholism, 2015).

\section{Health concerns associated with alcohol misuse}

Alcohol misuse contributes to a wide array of physical and mental health concerns. According to 2012 data from the World Health Organization (WHO), alcohol misuse is attributable to $5.1 \%$ of the global burden of disease and injury and about $5.9 \%$ of deaths globally (about 3.3 million): "The harmful use of alcohol ranks among the top five risk factors for disease, disability and death throughout the world" (p. 2). Mental and substance abuse disorders are the leading cause of "years lived with a disability" (YDLs) world-wide, with alcohol use disorders accounting for 9.6\% of YDLs (Whiteford et al., 2013). Specifically, alcohol misuse is related to the prevalence and incidence of accidental injury, infectious disease exposure (e.g., HIV risk behaviors), and other diseases (e.g., diabetes, hypertension, stomach ulcers, heart attack/failure, liver disease, various forms of cancer) (Nolen-Hoeksema, 2004; Rehm \& Hingson, 2013). In the United States, alcohol is among the leading risk factors for mortality and is a recognized contributor to the top 10 causes of death, including heart disease, cancer, stroke, fatal injuries, and suicide (Centers for Disease Control and Prevention, 2014). Alcohol misuse is often found in adults to be comorbid with memory/cognitive impairment and major depressive, bipolar, and other cognitive and emotional impairments. And, fetal alcohol exposure is associated with an increased risk of neurodevelopmental disorders and birth defects on a spectrum, the most extreme of which may be diagnosed as fetal alcohol syndrome. ${ }^{1}$

\section{Social problems associated with alcohol misuse}

Alcohol misuse also is a recognized risk factor for numerous large-scale social problems for which social workers provide assessment, prevention and treatment intervention, programs, and policy recommendations. Examples include the perpetration of intimate partner violence (Maldonado, Watkins, DeLillo, 2015; Peralta, Tuttle, \& Steele, 2010), parental child maltreatment (Freisthler \& Holmes, 2012), human trafficking (Bhunu \& Mushayabasa, 2012; Wiechelt \& Shdaimah, 2011), intentional and nonintentional injury (Cunningham et al., 2011), problem gambling (Griffiths, Wardle, Orford, Sproston, \& Erens, 2011), school failure (Kelly, 2015), community-level distress (Flynn \& Wells, 2013), housing insecurity/homelessness (Kirst, Zerger, Misir, Hwang, \& Stergiopoulos, 2015), criminal justice system involvement (Begun, Rose, LeBel, \& Teske-Young, 2009), sexual risk taking and unintended pregnancy (Walton et al., 2011; Xaverius, Tenkku, \& Salas, 2009), sexual assault (BuschArmendariz, DiNitto, Bell, \& Bohman, 2010), and suicidality (Cherpitel, Borges, \& Wilcox, 2004; Kennedy et al., 2015).

\section{Alcohol misuse among youth}

Alcohol misuse has proven particularly problematic for youth. Fetal alcohol exposure contributes to a spectrum of preventable birth defects and neurodevelopmental challenges with lifelong implications (Sokol, DelaneyBlack, \& Nordstrom, 2003; Velasquez, von Sternberg, \& Parrish, 2013; Waterman, Pruett, \& Caughey, 2013). From a neurobiological perspective, the developing adolescent brain places teenagers at risk for substance misuse given youths' proclivities towards impulsivity, sensation seeking, and disregard of future outcomes; they also respond more to alcohol's reward stimuli compared to adults (McLoughlin, Gould, \& Malone, 2015). Adolescent alcohol use, especially among preteens, is a serious risk factor for suicidal ideation and suicide attempts in girls and boys; for example, youth who reported an episode of heavy episodic drinking during the past year were significantly more likely to report a suicide attempt than peers who did not (McLoughlin, Gould, \& Malone, 2015). In addition, the use of alcohol while feeling depressed is correlated with suicidal behavior among adolescents (McLoughlin, Gould, \& Malone, 2015). In terms of health trajectories, early onset of first use of alcohol (for youth aged between 11 and 14 years) significantly increases the risk of an alcohol use disorder later in life; therefore, preventing adolescent alcohol use is a reasonable target for intervention strategies (DeWit, Adlaf, Offord, \& Ogborne, 2000). College students and young adults also experience high rates of alcohol-related problems stemming from heavy use patterns and drinking in high-risk contexts (Clapp et al., 2009; Johnston et al., 2010; Reed et al., 2013). Alcohol

\footnotetext{
${ }^{1}$ See http://www.cdc.gov/ncbddd/fasd/facts.html.
} 
poisonings among individuals aged 18 to 24 years, for instance, have increased over $190 \%$ over the past two decades (R. Hingson, personal communication, May, 2012).

\section{The role of social work}

- Alcohol misuse is a compelling and critical problem for social work because social workers encounter alcohol misuse in a broad range of practice settings. It directly or indirectly relates to every domain of wellbeing about which the profession is concerned: achieving basic needs for individuals and families (e.g., housing security), health and safety, social relationships, personal fulfillment/self-actualization, healthy communities and social institutions, social policy, public health, and global relations. This concept paper is focused primarily on the safety and health domains, and emphasizes the complexity of the problems associated with alcohol misuse: Alcohol problems are truly biopsychosocial in nature, which is a core tenet of the social work profession.

- Alcohol misuse is a lifespan issue related to negative developmental consequences of prenatal exposure; abnormal brain development in childhood; family disorganization and child maltreatment; negative physical and social consequences of binge drinking during adolescence and emerging adulthood; and problems that occur during early, middle, and late adulthood involving addiction, alcohol attributable diseases, injury, and medication interactions.

- Alcohol misuse is a problem with multiple political and economic dimensions. It ranges from individuals' internal biological, genetic, physiological, and psychological systems to the interpersonal, group, neighborhood, institutional, regional, national, and global levels.

- It requires multisectoral collaboration to study and develop effective solutions.

- Distinct addressable disparities exist in terms population vulnerabilities, the distribution of the problems associated with alcohol misuse, and access to evidence-informed prevention and treatment services.

For these reasons, social work has a prominent role to play in resolving the Grand Challenge of reducing and preventing negative consequences associated with alcohol misuse.

\section{The Challenge Can Be Analyzed, Assessed, and Alleviated}

Alcohol research includes measures ranging from individual treatment responses at the micro- level (e.g., neuroscience, genomics, epigenetics, proteomics, metabolomics) to macro-level studies (e.g., populationbased epidemiology, econometrics, health/human services, policy-level interventions). Contemporary research methodologies for studying alcohol misuse include community-based participatory research studies (CBPR) and rich descriptive approaches (e.g., qualitative, phenomenological, narrative, ethnographic); experimental (e.g., single system to randomized controlled and comparative effectiveness trials); cost-effectiveness; systematic review; meta-analysis; network analysis; and studies of policy effects at local, state, regional, national, and global levels. Researchers increasingly use systems science (e.g., big data, "big data, small $n$ " studies), data analytics, agent-based modeling, and dynamical/ computational simulation to study alcohol-related behaviors (Gorman, Mezic, Mezic, \& Gruenewald, 2006; Scribner et al., 2009). Investigators leverage emerging technologies to capture real-time data (e.g., ecological momentary assessments, geo-spatial tracking) and microunit data points that can be used to create complex pictures of alcohol-related behaviors and events, as well as other environmental influences (Cohn, Hunter-Reel, Hagman, \& Mitchell, 2011). And, intervention science addresses translational science aspects including dissemination and implementation science, in addition to answering "what works" and mechanisms of change questions.

\section{Applying research to affect change}

Despite variations in methods across such approaches the Grand Challenge of reducing alcohol misuse and its associated consequences can be analyzed, assessed, and alleviated. The challenge can be met by drawing on varied methods and scientific traditions, and facilitating multisectoral triangulation of findings.

With this rich diversity of conceptual, methodological, and analytical approaches comes great opportunity. Problems related to alcohol misuse are proving to be changeable. For example, youthful drivers were involved in fewer alcoholrelated crashes with the advent and enforcement of minimum drinking-age legislation (Wagenaar \& Toomey, 2002) and driving under the influence across the whole population of individuals aged 12 years and older declined by 3\% between 2002 and 2012 (National Institute on Drug Abuse, 2014). Among parents involved with the child welfare system who experience substance abuse problems, completing substance abuse treatment significantly contributes to greater likelihood of child reunification and less time that children spend in foster care (Marlowe \& Carey, 2012). Heavy alcohol use and binge drinking during pregnancy declined between the 2008 through 2011 periods, although the number of pregnant women drinking alcohol at all did not appear to decline (SAMHSA, 2011). Rates of alcoholic liver disease showed a marked decline from 1970 to 2000; however, liver cirrhosis deaths (often caused by alcohol misuse) remained disproportionately high among both black non-Hispanic and white Hispanic individuals (Mann, Smart, \& Govoni, 2004; NIAAA, 2001). To reduce the burden of disease related to alcohol use and alcohol use disorders, "implementation of prevention interventions and expansion of treatment are necessary” (Rehm et al., 2014, p. 1068).

\section{Innovative organization of research}

Research and interventions related to alcohol misuse are increasingly being linked in innovative ways by employing an array of methodologies, involving numerous disciplines, and applying a variety of technologies to achieve national 
and international reach. For example, the Higher Education Center for Alcohol and Drug Misuse Prevention and Recovery (HEC) at The Ohio State University is being built to move prevention and recovery research into colleges and universities nationally as a means of preventing alcohol misuse, consequences associated with alcohol misuse, and alcohol use disorders. By developing smart technologies, using systems dynamic modeling to develop simulation tools, and harnessing social media to generate "big data," HEC is systematically employing novel strategies for the rapid translation of science models. A partnership of professionals working in prevention and recovery, HEC engages researchers from multiple disciplines (e.g., social work, engineering, geography, pharmacy, social psychology). This model is one example that illustrates how "bringing the pieces together" is not only possible but also likely the key to meeting this Grand Challenge.

Disseminating emerging knowledge to practitioners at individual, family, community, and larger systems levels is another opportunity to further alleviate alcohol misuse in innovative ways. Professional development curricula that tap into the evidence base related to alcohol misuse integrate knowledge into professional education systems to improve the well-being of individuals at risk for developing alcohol or other substance use disorders. These opportunities prepare individuals in several professions (e.g., social work, nursing, medicine, clergy) to work with individuals and families affected by alcohol problems to implement prevention strategies. Interdisciplinary curricula are also available for practitioners who deliver screening, brief intervention, and referral to treatment (SBIRT), and to prepare substance abuse clinical researchers in the health professions (e.g., Substance Abuse Research Education and Training [SARET]). The advent of open source online training mechanisms (e.g., iTunes U, Coursera, Udacity, edX) and University-based online courses, present additional opportunities for both preservice and inservice/continuing education related to this Grand Challenge.

\section{Demonstrable Progress toward the Challenge Can Be Made in a Decade}

In 2010, the National Institute on Alcohol Abuse and Alcoholism produced a review of progress in alcohol research over the first 40 years since it became the lead Federal agency for conducting and funding research on alcohol-related problems in the United States (Warren \& Hewitt, 2010). The report documents accomplishments related to a better understanding of the epidemiology and etiology of alcohol use disorders, strategies for treating and preventing alcohol use disorders, and the effects of alcohol on various aspects of health and human functioning.

The rate of new knowledge and innovation being generated continues to accelerate. Large-scale, national epidemiological surveys - the National Epidemiologic Survey on Alcohol and Related Conditions, National Survey on Drug Use and Health, and Monitoring the Future-shed light on population trends in alcohol misuse and alcohol use disorders over time and across population subgroups. Enormous strides have been made in understanding the complex genetics and epigenetic mechanisms in developing alcohol use disorders, in large part due to the multidisciplinary, multisite Collaborative Study on Genetics of Alcoholism (Edenberg, 2003). Study of the problem's etiology has also been stimulated by the use of ecological momentary assessment methodologies whereby investigators gain insight about craving, use, and environmental influences on behavior "in the moment" rather than relying on retrospective reporting (Moskowitz \& Young, 2006). Intervention research efforts have resulted in a strong evidence base and numerous collaborative efforts among social work and allied health programs supporting the application of approaches for early identification and screening for possible alcohol use disorders, and for using SBIRT (Barbosa, Cowell, Bray, \& Aldridge, 2015; Mitchell, Gryczynski, O’Grady, \& Schwartz, 2013). New promising treatment approaches that combine pharmacotherapies and behavioral therapies have emerged (Jonas et al., 2014; Miller, Locastro, Longabaugh, O’Malley, \& Zweben, 2005). Evidence supports the use of drug courts as systems for coordinating and judicially supervising treatment for individuals involved with the criminal justice system as a result of problems with alcohol or other drugs (Brown, Allison, \& Nieto, 2011) and for families involved in the child welfare system (Green, Furrer, Worcel, Burrus, \& Finigan, 2007; Smith, 2003). Increasing evidence supports alcohol treatment protocols delivered via computer or mobile devices, or traditional face-to-face approaches being supported by smartphone technology, in addition to treatments that integrate data from ecological momentary assessment (Cohn et al., 2011; Hasin, Aharanovich, \& Greenstein, 2014; White et al., 2010). Finally, there are numerous macro-level examples of alcohol control interventions including drunk-driving prevention, responsible beverage service, and controlling alcohol outlet density (Clapp et al., 2005; Community Preventive Services Task Force, 2015; Gruenewald, 2007; Gruenewald, Freisthler, Remer, LaScala, \& Treno, 2006; Holder, Saltz, Gruber, Treno et al., 1997; Holder, Saltz, Gruber, Voas et al., 1997).

Efforts in these areas have led to development of a mature knowledge base regarding alcohol misuse and alcohol use disorders. However, tremendous disparities exist among and between demographic groups, communities, and nations in terms of rates for incidence and prevalence of alcohol problems, diagnosis and treatment, and prevention outcomes. Applying a "social determinants of health" lens contributed from the field of public health is an important way to move from theory to action in integration across multiple levels of science, policy, and interventionparticularly with regard to vulnerable and underserved populations (International Center for Alcohol Policies, 2009).

\section{Directions for current and future research}

Four important directions of current and future research can help resolve this Grand Challenge in the next decade. 


\section{Mechanisms of behavior change}

Alcohol treatment studies have begun to move beyond "what works" to developing an understanding of how and why treatment works, and how self-change occurs outside of treatment. This includes identifying the common elements in evidence-based approaches and common factors in successful behavior-change efforts for individuals who have the consequences of alcohol misuse. Mechanisms of behavior-change research can capitalize on emerging research methodologies and analytic techniques, as well as the wealth of evidence from previous studies about necessary components in effective prevention and treatment interventions.

\section{Effectiveness studies}

In this domain, researchers assess strategies known to work under controlled circumstances with diverse populations that are heterogeneous in terms of gender, ethnicity/race, nation/national origin, incarceration history, sexual orientation, cognitive and physical condition, and other forms of human diversity. Effectiveness studies also include real-world treatment contexts that include diverse types of settings beyond the specialized addiction treatment program and intervention delivery by a diverse range of providers (i.e., professionals from varied disciplines and individuals with differing levels of education/training, including paraprofessionals and natural helpers). Multisite study networks (e.g., the National Institute on Drug Abuse and Canadian clinical trials networks, the National Institutes of Health) support centers for clinical and translational science and provide new opportunities to conduct these studies with greater scientific integrity and generalizability of study results.

\section{Interdisciplinary and multilevel approaches}

Researchers and practitioners are increasingly working across traditional disciplinary and systemic boundaries to advance scientific inquiry and develop multilevel intervention strategies to address alcohol misuse. Integration is also taking place across subdisciplines in fields such as psychology (e.g., developmental, social, experimental, clinical), engineering (e.g., human, bio, systems science), public health (e.g., health behavior, biostatistics, epidemiology), and mathematics (e.g., agentbased modeling, computational science, big data, statistics). These endeavors are contributing to ever-greater understanding of biopsychosocial and transdisciplinary features related to alcohol misuse and its consequences. Concurrently, this type of work contributes to expanding knowledge concerning the ways in which novel interventions respond to the multiple levels at which "person in environment" systems operate (i.e., internal/individual, micro, meso, and macro systems).

\section{Translational and implementation science}

Major initiatives are being launched to develop the science around strategies that are most effective and efficient for treatment, prevention, policy, practitioner development, and service delivery systems. At one end of the translational science knowledge building continuum are epidemiology, etiology, and theory building/testing studies that can inform the development of prevention, treatment, and policy intervention strategies. At the other end are implementation science efforts that can help inform efforts to get evidence-informed interventions into mainstream practice (Proctor et al., 2009).

Access to appropriate prevention, early intervention, and treatment across diverse, vulnerable populations continues to be a challenge despite advances in science and policy. Moving these streams of work forward in a unified way and in the context of a challenging funding environment will require leadership, innovation, and the involvement and coordination of multiple stakeholders. Currently, many of the parts necessary for making this progress are accessible or emerging, making demonstrable progress possible over the next decade.

\section{Multisectoral Collaboration Is Required to Meet the Challenge}

Alcohol misuse and its consequences make up a complex systems problem. Numerous disciplines have examined the etiology of alcohol-related problems from multiple perspectives ranging from microbiology and genomics to macroeconomics and public policy. Similarly, solutions to alcohol-related problems have emerged from various subfields of biology, pharmacology, psychology, medicine and psychiatry, engineering, social work, public health, anthropology, nursing, occupational therapy, sociology, criminal justice, education, mathematics, public policy, economics, business, and law. Given the number of disciplines studying alcohol misuse, solutions to alcoholrelated problems are inherently multisectoral. The social work profession is a natural fit to lead the reduction of alcohol misuse and its consequences because it intersects and interfaces with the populations most likely to be affected by alcohol misuse. Social workers provide prevention, treatment, and intervention activities in multisectoral settings (e.g., hospitals, jails, schools, shelters, communities).

Collaboration between researchers and practitioners As multisectoral collaboration among alcohol researchers and practitioners expands, there are significant opportunities to promote theory, measures, design, analytic approaches, technologies, and implementation strategies that transcend traditional disciplinary boundaries. Many organizations ${ }^{2}$ include members from numerous academic fields and traditions (including social work), but have yet to launch a coordinated offense directed toward the Grand Challenge of significantly reducing alcohol misuse and its consequences.

\footnotetext{
2 Examples include The Research Society on Alcoholism, Mechanisms of Behavioral Change Study Group, Society for Prevention Research, Association for Medical Education and Research in Substance Abuse, International Society for Biomedical Research on Alcoholism, Asia-Pacific Society for Alcohol and Addiction Research, European Society for Biomedical Research on Alcoholism, Latin American Society for Biomedical Research on Alcoholism, and the Fetal Alcohol Spectrum Disorders Study Group.
} 


\section{Collaboration between governmental and nongovernmental organizations}

On a global level, governments and nongovernmental organizations play a critical role in meeting this challenge. The National Institute on Alcohol Abuse and Alcoholism has dedicated resources to helping nations around the world develop evidence-informed responses to alcohol misuse and its consequences, and the World Health Organization monitors the scope of the problem. Though member countries voted on the Global Strategies to Reduce Alcohol-Related Harms at the 2010 World Health Assembly, the global response to alcohol-related problems has much room to improve. In many parts of the developing world, there is inadequate funding for alcohol research, alcohol policies of varied effectiveness, and sustainable implementation of evidence-based alcohol prevention and treatment programs. More can be done in developed countries as well. Increased funding and coordination across multiple sectors including industry and government will likely be required to build the infrastructure to fund, develop, and test solutions to this challenge.

\section{Targeted collaboration with the alcohol industry}

The alcohol beverage and hospitality industries have long been viewed as adversaries to public health efforts aimed at reducing alcohol misuse. This has given rise to concerns regarding the influence of the beverage industry, including suggestions that the implementation of policies with a strong evidence base, such as minimum pricing and regulation of advertising, have been delayed or inhibited (Gilmore \& Daube 2014; Hill \& Casswell, 2004). Although the examples of irresponsible product development and advertising are plentiful, prevention approaches grounded in prohibition seldom work. A thoughtful, selective and more open approach to working with these stakeholders, including the National Alcohol Beverage Control Association and state licensure boards, will be vital for meeting this Grand Challenge. Many of the world's largest producers of alcohol are developing evidence-based programs to reduce the harms associated with alcohol misuse and have formed alliances such as the International Alliance for Responsible Drinking. Working with industries such as insurance companies, healthcare organizations, and casinos as potentially strong tactical partners is another strategy to consider for meeting the Grand Challenge. Advocates must think broadly and without ideological constraints.

\section{Sustainable Solutions to the Challenge Require Significant, Transformative, and Groundbreaking Innovations}

Rapid advances in technology and science, coupled with a growing comprehensive body of knowledge and professional practice, provide the basis for other areas of innovation. For this particular Grand Challenge, four interrelated areas of potential innovation can transform the current situation: structural innovations; scientific innovations; technological innovations; and prevention, treatment, and policy innovations.

\section{Structural innovations}

Structural innovations include developing mechanisms to bring the various academic, scientific, professional, governmental, and nongovernmental streams of together in a more unified, systematic manner to work on the alcohol misuse challenge. Developing systematic and coordinated roadmaps for action will require leadership, a substantial organizing effort, the development of common concepts and nomenclature, and summarizing the "state of the field" in an accessible way. Additionally, identifying and developing new models for the sale and taxation of alcohol, and the funding of research and solutions to alcohol-related problems at the individual, family, community, and larger system levels must occur. On the academic side, tenure and promotion systems will need to embrace team science, university-community collaborations, and multisectoral endeavors, a change that is slowly taking place nationally (Basken, 2015).

\section{Scientific innovations}

Innovations in science will likely occur naturally within the various subfields of alcohol research and other areas from which alcohol science can draw. Advances in numerous areas have occurred in recent years. The expansion of systems science and the study of complex systems will provide critical contributions and opportunities, as will the design of multilevel studies (e.g., Clapp et al., 2006; Galea, Hall, \& Kaplan, 2009). Major opportunities for exponential advances will occur by developing mechanisms for the various alcohol research subfields to integrate more complexity into theory and methods. Adoption of new clinical substance use disorder definitions (i.e., the Diagnostic and Statistical Manual of Mental Disorders fifth edition [DSM-5], the International Classification of Diseases version 10 [ICD-10]) necessitate innovations in measurement science as the entire field of applied addiction study moves forward. Emerging biomarker and behavioral genetic science arenas are also becoming ideally positioned to inform innovations in assessment, diagnosis, treatment, and prevention.

\section{Technological innovations}

Health behavior models have failed to keep pace with rapid mobile technological innovations (Riley et al., 2011). For example, portable tools for self-monitoring one's blood alcohol levels, the effect of alcohol levels on other biological/physiological functions, and personal spending on alcohol are emerging on the market (e.g., the Breeze Breathometer, credit and debit card purchases paired with smartphone health tracking apps). As technological innovations progress, researchers and practitioners will be challenged with the need to balance and more fully understand the ecological factors important to target when intervening (e.g., when/where to intervene in time and space). Though these innovations might provide opportunities for research and intervention, they also will likely introduce new challenges that need to be addressed. For example, the potential sale of alcohol via the Internet complicates efforts to limit access by underage populations. Furthermore, when layered with geopolitical changes and economic disparities, technological innovations related to alcohol problems will likely raise distributive justice issues. 
For instance, on one hand, as automotive technology evolves toward less and less driver control, and driverless vehicles become common in wealthier nations, drunk driving crashes will likely decrease drastically The Ford Motor Company's chief executive officer estimates that all new vehicles in the U.S. will be equipped with driverless technology in the next 15 years (Rosenbush, 2015). On the other hand, this change could flood poorer nations with older, driver-operated vehicles exported from the United States and affect drunk driving patterns in nations where vehicles were not previously as commonly available. Global leadership on this and similar issues is critical.

\section{Prevention and treatment innovations}

As noted above, the science around the etiology, prevention, and treatment of alcohol problems has advanced in recent years. Social work scholars are well represented among authors and editors of important textbooks on these topics (e.g., McNeece \& DiNitto, 2012; Miller, Forcehimes, \& Zweben, 2011; Straussner, 2014; Straussner \& Fewell, 2011; van Wormer \& Davis, 2013; van Wormer \& Thyer, 2010; Vaughn \& Perron, 2013). True innovations in the prevention and treatment sectors are possible through multisectoral collaboration. For instance, models that integrate pharmacological, motivational, or cognitive/behavioral therapies with biometric monitoring and "smart" technology might prove effective, but they will require new training for professionals, reimbursement models, and case management systems. Additionally, environmental policies and partnerships between behavioral and computer scientists will need to support innovations that include ecological approaches that attempt to interrupt problem behaviors in situ using smart technologies based on situational dynamics.

Continued advances in the translation of science to practice remain an essential priority to solve the challenge of alcohol misuse. Evidence-based community intervention and prevention efforts are necessary because effective integration of alcohol prevention and treatment strategies into routine practice requires significant "cultural" adaptations, particularly in community settings where social norms run counter to the aim of reducing alcohol misuse (Holleran Steiker, 2008; Holleran Steiker, Grahovac, \& White, 2014). Large-scale data mining efforts with human services data, development of culturally sensitive measurement and intervention, and applying epigenetic research to risk assessment are important innovative steps in moving alcohol misuse prevention and treatment forward.

\section{Conclusion}

Given the current fragmentation of responses to alcoholrelated problems at the academic and governmental levels, it is not surprising that findings from scientific studies often fail to fully inform practice in prevention, treatment, and recovery for alcohol-related practice and policy. The study of and practice surrounding alcohol misuse and its consequences are at a critical precipice. There is a great opportunity and need to rapidly move science from "bench to bedside;" however, doing so effectively and efficiently requires social work to assume a leading role in augmenting and orchestrating a cohesive community of interdisciplinary scientists, prevention and treatment providers, business, policy makers, and citizens across the United States and the world. Alcohol misuse has an impact on every population and domain of well-being around which social workers assess, intervene, evaluate, advocate, conduct research, or inform policy. The case has been made: Though the Grand Challenge to reduce and prevent alcohol misuse and its consequences is monumental, progress is achievable with a commitment to a collaborative and sustainable spirit and an appreciation for groundbreaking innovation.

\section{Acknowledgments}

The authors would like to acknowledge John Gabbert at the Center for Social Development who provided editorial support.

\section{References}

Basken, P. (2015) Team science: Research cooperation grows as federal money tightens. Chronicle of Higher Education. Retrieved from http://chronicle.texterity. com/chronicle/20150313b

Barbosa, C., Cowell, A., Bray, J., \& Aldridge, A. (2015). The cost-effectiveness of alcohol screening, brief intervention, and referral to treatment (SBIRT) in emergency and outpatient medical settings. Journal of Substance Abuse Treatment, 53, 1-8. doi: 10.1016/ j.jsat.2015.01.003

Begun, A.L. (in press). Substance use disorders. Chapter to appear in S. A. Kapp (Ed.), Introduction to social work, Thousand Oaks, CA, United States: Sage Publications.

Begun, A. L., Rose, S. J., LeBel, T. P., \& Teske-Young, B. A. (2009). Implementing substance abuse screening and brief motivational intervention with women in jail. Journal of Social Work Practice in the Addictions, 9, 113-131. doi:10.1080/15332560802533372

Bhunu, C. P., \& Mushayabasa, S. (2012). Prostitution and drug (alcohol) misuse: The menacing combination. Journal of Biological Systems, 20(2), 177-194. doi:10.1142/S0218339012500052

Brown, R. T., Allison, P. A., \& Nieto, F. J. (2011). Impact of jail sanctions during drug court participation upon substance abuse treatment completion. Addiction, 106(1), 135-142.

Busch-Armendariz, N. B., DiNitto, D. M., Bell, H., \& Bohman, T. (2010). Sexual assault perpetrators' alcohol and drug use: The likelihood of concurrent violence and post-sexual assault outcomes for women victims. Journal of Psychoactive Drugs, 42(3), 393399.

Centers for Disease Control and Prevention (CDC). (2014). CDC national health report: Leading causes of morbidity and mortality and associated behavioral 
risk and protective factors-United States, 2005-2013. Retrieved from http://stacks.cdc.gov/view/cdc/25809

Cherpitel, C. J., Borges, G. L., \& Wilcox, H. C. (2004). Acute alcohol use and suicidal behavior: A review of the literature. Alcoholism: Clinical and Experimental Research, 28(Suppl 5), 18S-28S.

Clapp, J. D., Johnson, M., Boas, R. B., Lange, J. E., Shillington, A., \& Russell, C. (2005). Reducing DUI among U.S. college students: Results of an environmental prevention trial. Addiction, 100(3), 327-334.

Clapp, J. D., Min, J. W., Shillington, A. M., Reed, M. B., Lange, J. E., \& Holmes, M. R. (2006). Environmental and individual predictors of error in field estimates of blood alcohol concentration: A multilevel analysis. Journal of Studies on Alcohol, 67(4), 620-628.

Clapp, J. D., Reed, M. B., Min, J. W., Shillington, A. M., Croff, J., Holmes, M. R., \& Trim, R. (2009). Blood alcohol concentrations among bar patrons: A multilevel study of drinking behavior. Drug and Alcohol Dependence, 102, 41-48.

Cohn, A. M., Hunter-Reel, D., Hagman, B. T., \& Mitchell, J. (2011). Promoting behavior change from alcohol use through mobile technology: The future of ecological momentary assessment. Alcoholism: Clinical and Experimental Research, 35(12), 2209 2215. doi:10.1111/j.1530-0277.2011.01571.x

Community Preventive Services Task Force. (2015). Preventing excessive alcohol consumption. Retrieved from http://www.thecommunityguide.org/alcohol/ index.html

Cunningham, R. M., Walton, M. A., Harrison, S. R., Resko, S. M., Stanley, R., Zimmerman, M., . . . \& Shope, J. T. (2011). Past-year intentional and unintentional injury among teens treated in an inner-city emergency department. The Journal of Emergency Medicine, 41(4), 418-426.

Dawson, D. A., Goldstein, R. B., Saha, T. D., \& Grant, B. F. (2015). Changes in alcohol consumption: United States 2001-2002 to 2012-2013. Drug and Alcohol Dependence, 148, 56-61. doi:0.1016/j.drugalcdep. 2014.12.016.Epub 2014 Dec 23.

DeWit, D. J., Adlaf, E. M., Offord, D. R., \& Ogborne, A. C. (2000). Age at first alcohol use: A risk factor for the development of alcohol disorders. American Journal of Psychiatry, 157, 745-750.

Edenberg, H. J. (2003). The collaborative study on the genetics of alcoholism: An update. National Institutes of Health, National Institute on Alcohol Abuse and Alcoholism. Retrieved from http://pubs.niaaa.nih.gov/ publications/arh26-3/214-218.htm

Flynn, A., \& Wells, S. (2013). Community indicators: Assessing the impact of alcohol use on communities. Alcohol Research: Current Reviews, 35(2), 135-149.

Freisthler, B., \& Holmes, M. (2012). Explicating the social mechanisms linking alcohol use behaviors and ecology to child maltreatment. Journal of Sociology \& Social Welfare, 39(4), 25-48.

Galea, S., Hall, C., \& Kaplan, G. A. (2009). Social epidemiology and complex system dynamic modelling as applied to health behaviour and drug use research. International Journal of Drug Policy, 20, 209-216.
Gill, J. S., Shipley, M. J., Hornby, R. H., Gill, S. K., \& Beevers, D. G. (1988). A community case-control study of alcohol consumption in stroke. International Journal of Epidemiology, 17, 542-547.

Gilmore, I., \& Daube, M. (2014). How a minimum unit price for alcohol was scuppered. British Medical Journal, 348, g 23.

Green, B. L., Furrer, C. J., Worcel, S. D., Burrus, S. W. M., \& Finigan, M. W. (2007). How effective are family treatment drug courts? Results from a 4-site national study. Child Maltreatment, 12(1), 43-59.

Griffiths, M., Wardle, H., Orford, J., Sproston, K., \& Erens, B. (2011). Internet gambling, smoking and alcohol use: Findings from the 2007 British Gambling Prevalence Survey. International Journal of Mental Health \& Addiction, 9(1), 1-11.

Gruenewald, P. J. (2007). Addiction and its sciences. The spatial ecology of alcohol problems: Niche theory and assortative drinking. Addiction, 102(6), 870-878.

Gruenewald, P. J., Freisthler, B., Remer, L., LaScala, E. A., \& Treno, A. (2006). Research report. Ecological models of alcohol outlets and violent assaults: Crime potentials and geospatial analysis. Addiction, 101(5), 666-677.

Gorman, D. M., Mezic, J., Mezic, I., \& Gruenewald, P. J. (2006). Agent-based modeling of drinking behavior: A preliminary model and potential applications to theory and practice. American Journal of Public Health, 96(11), 2055-2060.

Hanson, G. R., Venturelli, P. J., \& Fleckenstein, A. E. (2015). Drugs and society (12 ${ }^{\text {th }}$ edition). Burlington, MA, United States: Jones \& Bartlett Learning.

Hasin, D., Aharanovich, E., \& Greenstein, E. (2014). HealthCall for the smartphone: Technology enhancement of brief intervention in HIV alcohol dependent patients. Addiction Science \& Clinical Practice, 9(1), 5-12.

Hill, L., \& Casswell, S. (2004). Alcohol advertising and sponsorship: Commercial freedom or control in the public interest? In N. Heather \& T. Stockwell, (Eds.), The essential handbook of treatment and prevention of alcohol problems, (pp. 339-362). Chichester, PA, United States: Wiley \& Sons.

Holbrook, T. L., \& Barrett-Conner, E. A. (1993). A prospective study of alcohol consumption and bone mineral density. British Journal of Medicine, 306, 1506-1509.

Holder, H. D., Saltz, R. F., Gruber, J. W., Treno, A. J., Reynolds, R. I., Voas, R. B., \& Gruenewald, P. J. (1997). Summing up: Lessons from a comprehensive community prevention trial. Addiction, 92(Suppl. 2), S293-S301.

Holder, H. D., Saltz, R. F., Gruber, J. W., Voas, R. B., Gruenewald, P. J., \& Treno, A. J. (1997). A community prevention trial to reduce alcohol-involved injury and death: Overview. Addiction, 92(Suppl 2), S155-S171.

Holleran Steiker, L. K. (2008). Making drug and alcohol prevention relevant: Adapting evidence-based curricula to unique adolescent cultures. Family \& Community Health, 31(1S), S52-S60. 
Holleran Steiker, L. K., Grahovac, I., \& White, W. (2014). Social work and collegiate recovery communities. Social Work, 59(2), 177-180.

Howard, M. O., Garland, E. L., \& Whitt, A. (2013). Historical and contemporary perspectives, (pp. 3-21). In M. G. Vaughn \& B. E. Perron, (Eds.), Social work practice in the addictions. New York, NY, United States: Springer.

International Center for Alcohol Policies. (2009). Determinants of drinking. Washington, DC, United States. Retrieved from http://www.icap.org/ LinkClick.aspx?fileticket=opSlJDbBI\%2BU\%3D\&tab id $=243$

Johnston, L. D. (2010). Monitoring the future: National survey results on drug use, 1975-2008: Volume II: College students and adults ages 19-50. Darby, PA, United States: Diane Publishing.

Jonas, D. E., Amick, H. R., Feltner, C., Bobashev, G., Thomas, K., Wines, R., . . . Garbutt, J. C. (2014). Pharmacotherapy for adults with alcohol use disorders in outpatient settings: A systematic review and metaanalysis. Journal of the American Medical Association 311(18), 1889-1990.

Karlamangla, A. S., Sarkisian, C. A., Kado, D., Dedes, H., Liao, D. H., Kim, S., Reuben, D. B., Greendale, G. A., \& Moore, A. A. (2009). Light to moderate alcohol consumption and disability: Variable benefits by health status. American Journal of Epidemiology, 169(1), 96-104.

Kelly, A. B. (2015). A longitudinal study of the association of adolescent polydrug use, alcohol use and high school non-completion. Addiction, 110(4), 627-635.

Kennedy, M. C., Marshall, K. H., Hayashi, K., Nguyen, P., Wood, E., \& Kerr, T. (2015). Heavy alcohol use and suicidal behavior among people who use illicit drugs: A cohort study. Drug and Alcohol Dependence, 151, 272-277. doi:10.1016/j.drugalcdep.2015.03.006

Kirschstein, R. (2000). Disease-specific estimates of direct and indirect costs of illness and NIH support: Fiscal year 2000 update. Bethesda, MD, United States: National Institutes of Health.

Kirst, M., Zerger, S., Misir, V., Hwang, S., \& Stergiopoulos, V. (2015). The impact of a Housing First randomized controlled trial on substance use problems among homeless individuals with mental illness. Drug and Alcohol Dependence, 146, 24-29.

Klatsky, A. L. (1999). Moderate drinking and reduced risk of heart disease. Alcohol Research \& Health, 23(1), 15-23.

Koppes, L. L., Dekker, J. M., Hendriks, H. F., Boutler, L. M., \& Heine, R. J. (2005). Moderate alcohol consumption lowers the risk of type 2 diabetes: A meta-analysis of prospective observational studies. Diabetes Care, 28, 719-725.

Maldonado. R. C., Watkins, L. E., \& DeLillo, D. (2015). The interplay of trait anger, childhood physical abuse, and alcohol consumption in predicting intimate partner aggression. Journal of Interpersonal Violence, 30(7), 1112-1127. doi:10.1177/0886260514539850

Mann, R. E., Smart, R. G., \& Govoni, R. (2004). The epidemiology of alcoholic liver disease. National Institute on Alcohol Abuse and Alcoholism. Retrieved from http://pubs.niaaa.nih.gov/publications/arh27-3/ 209-219.htm

Marlowe, D. B., \& Carey, S. M. (2012). Research update on family drug courts. Alexandria, VA, United States: National Association of Drug Court Professionals.

McGovern, P. E. (2009). Uncorking the past: The quest for wine, beer, and other alcoholic beverages. Berkeley, CA, United States: University of California Press.

McLoughlin, A. B., Gould, M. S., \& Malone, K. M. (2015). Global trends in teenage suicide: 2003-2014. QJM: An International Journal of Medicine, 108(10), 765780. doi:10.1093/qjmed/hcv026

McNeece, C. A., \& DiNitto, D. M. (2012). Chemical dependency: A systems approach ( $4^{\text {th }}$ edition). Boston, MA, United States: Pearson.

Miller, W. R., Forcehimes, A. A., \& Zweben, A. (2011). Treating addiction: A guide for professionals. New York, NY, United States: Guilford Press.

Miller, W. R., Locastro, J. S., Longabaugh, R., O’Malley, S., \& Zweben, A. (2005). When worlds collide: Blending the divergent traditions of pharmacotherapy and psychotherapy outcome research. Journal of Studies on Alcohol, s15, 17-23.

Mitchell, S. G., Gryczynski, J., O’Grady, K. E., \& Schwartz, R. P. (2013). SBIRT for adolescent drug and alcohol use: Current status and future directions. Journal of Substance Abuse Treatment, 44(5), 463472.

Moskowitz, D. S., \& Young, S. N. (2006). Ecological momentary assessment: What it is and why it is a method of the future in clinical psychopharmacology. Journal of Psychiatry \& Neuroscience, 31(1), 13-20.

National Institute on Alcohol Abuse and Alcoholism (NIAAA). (2001). NIAAA analysis reveals increased risk for liver cirrhosis death among Hispanic Americans. Retrieved from http://www.niaaa.nih.gov/ news-events/news-releases/niaaa-analysis-revealsincreased-risk-liver-cirrhosis-death-among-hispanic

National Institute on Drug Abuse (NIDA). (2014). Drug Facts: Nationwide Trends. Retrieved from http://www.drugabuse.gov/publications/drugfacts/nati onwide-trends

Neafsey, E. J., \& Collins, M. A. (2011). Moderate alcohol consumption and cognitive risk. Neuropsychiatric Disease and Treatment, 7, 465-484.

Nolen-Hoeksema, S. (2004). Gender differences in risk factors and consequences for alcohol use and problems. Clinical Psychology Review, 24, 981-1010.

Peralta, R., Tuttle, L., \& Steele, J. (2010). At the intersection of interpersonal violence, masculinity, and alcohol use: The experiences of heterosexual male perpetrators of intimate partner violence. Violence Against Women, 16(4), 387-409.

Proctor, E. K., Landsverk, J., Aarons, G., Chambers, D., Glisson, C., \& Mittman, B. (2009). Implementation research in mental health services: An emerging science with conceptual, methodological, and training challenges. Administration and Policy in Mental Health and Mental Health Services Research, 36(1), 24-34.

Reed, M. B., Clapp, J. D., Weber, M., Trim, R., Lange, J., \& Shillington, A. M. (2011). Predictors of partying 
prior to bar attendance and subsequent BrAC. Addictive Behaviors, 36(12), 1341-1343.

Rehm, J., Dawson, D., Frick, U., Gmel, G., Roerecke, M., Shield, K. D., \& Grant, B. (2014). Burden of disease associated with alcohol use disorders in the United States. Alcoholism: Clinical and Experimental Research, 38(4), 1068-10778. doi:10.1111/acer.12331

Rehm, J., \& Hingson, R. (2013). Measuring the burdenAlcohol's evolving impact on individuals, families, and society. Alcohol Research: Current Reviews, 35(2), 122-127.

Research Society on Alcoholism (RSA). (2015). White paper: Impact of alcoholism and alcohol induced disease and disorders on America. Retrieved from http://rsoa.org/RSA2014WhitePaperFinalVersionVH.pdf

Riley, W. T., Rivera, D. E., Atienza, A. A., Nilsen, W., Allison, S. M., \& Mermelstein, R. (2011). Health behavior models in the age of mobile interventions: are our theories up to the task? Translational Behavioral Medicine, 1(1), 53-71.

Rosenbush, S. (2015, April 7). Ford CEO Expects Fully Self-Driving Cars within 15 Years. CIO Journal. Retrieved from http://blogs.wsj.com/cio/2015/04/07/ ford-ceo-expects-fully-self-driving-cars-within-15years/

Sampson, H. W. (2003). Alcohol and other factors affecting osteoporosis risk in women. Retrieved from http://pubs.niaaa.nih.gov/publications/arh26-4/292298.htm

Scribner, R., Ackleh, A. S., Fitzpatrick, B. G., Jacquez, G., Thibodeaux, J. J., Rommel, R., \& Simonson, N. (2008). A systems approach to college drinking: Development of a deterministic model for testing alcohol control policies. Journal of Studies on Alcohol and Drugs, 70(5), 805-821.

Singer, M. (2012). Anthropology and addiction: An historical review. Addiction, 107(10), 1747-1755. doi:10.1111/j.1360-0443.2012.03879.

Smith, B. D. (2003). How parental drug use and drug treatment compliance are related to family reunification. Child Welfare, 82, 109-127.

Sokol, R. J., Delaney-Black, V., \& Nordstrom, B. (2003). Fetal alcohol spectrum disorder. Journal of the American Medical Association, 290(22), 2996-2999.

Straussner, S. L. A., (Ed.). (2014). Clinical work with substance-abusing clients, $3^{\text {rd }}$ edition. New York, NY, United States: Guilford Press.

Straussner, S. L. A., \& Fewell, C. H., (Eds.). (2011). Children of substance abusing parents: Dynamics and treatment. New York, NY, United States: Springer Publishing Company.

Substance Abuse and Mental Health Administration (SAMHSA). (2014). Results from the 2013 National Survey on Drug Use and Health: Summary of National Findings. Retrieved from http://www.samhsa.gov/ data/sites/default/files/NSDUHresultsPDFWHTML20 13/Web/NSDUHresults2013.pdf
Substance Abuse and Mental Health Services Administration (SAMHSA). (2011). NSDUH results tables. Retrieved from http://www.samhsa.gov/data/ sites/default/files/NSDUH-

DetTabsPDFWHTML2011-web/NSDUHDetTabsPDFWHTML2011/PDFW/NSDUHDetTabsSect6seTabs71to78-2011.pdf

van Wormer, K., \& Davis, D. R. (Eds.) (2013). Addiction treatment: A strengths perspective. Belmont, CA, United States: Brooks/Cole, Cengage Learning.

van Wormer, K., \& Thyer, B. (Eds.). (2010). Evidencebased practice in the field of substance abuse: A book of readings. Thousand Oaks, CA, United States: Sage.

Vaughn, M. G., \& Perron, B. E. (Eds.). (2013). Social work practice in the addictions. New York, NY, United States: Springer Publishing.

Velasquez, M. M., von Sternberg, K., \& Parrish, D. E. (2013). CHOICES: An integrated behavioral intervention to prevent alcohol-exposed pregnancies among high-risk women in community settings. Social Work in Public Health, 28(3-4), 224-233.

Wagenaar, A. C., \& Toomey, T. L. (2002). Effects of minimum drinking age laws: Review and analyses of the literature from 1960 to 2000. Journal of Studies on Alcohol, s14, 206-225.

Walton, M. A., Resko, S., Whiteside, L., Chermack, S. T., Zimmerman, M., \& Cunningham, R. M. (2011). Sexual risk behaviors among teens at an urban emergency department: Relationship with violent behaviors and substance use. Journal of Adolescent Health, 48(3), 303-305.

Waterman, E. H., Pruett, D., \& Caughey, A. B. (2013). Reducing fetal alcohol exposure in the United States. Obstetrical \& Gynecological Survey, 68(5), 367-378.

White, A., Kavanagh, D., Stallman, H., Klein, B., KayLambkin, R., Proudfoot, J., ... . Young, R. (2010). Online alcohol interventions: A systematic review. Journal of Medical Internet Research, 12(5), e62. doi:10.2196/jmir.1479.

Whiteford, H. A., Degenhardt, L., Rehm, J., Baxter, A. J., Ferrari, A. J., . . . Vos, T. (2013). Global burden of disease attributable to mental and substance use disorders: Findings from the Global Burden of Disease Study 2010. Lancet, 382, 1575-1586.

Wiechelt, S. A., \& Shdaimah, C. S. (2011). Trauma and substance abuse among women in prostitution: Implications for a specialized diversion program. Journal of Forensic Social Work, 1(2), 159-184.

World Health Organization. (2014). Global status report on alcohol and health. Retrieved from http://www.who. int/substance_abuse/publications/global_alcohol_repor t/en/

Xaverius, P. K., Tenkku, L. E., \& Salas, J. (2009). Differences between women at higher and lower risk for an unintended pregnancy. Women's Health Issues, 19(5), 306-312. 


\section{Appendix A}

\section{The Alcohol Misuse Grand Challenge Collective}

Lisa Berger

University of Wisconsin-Milwaukee

Elizabeth Bowen

University at Buffalo

Joan Carlson

Indiana University

Jordan Davis

University of Illinois at Urbana-Champaign

Thomas Davis

University of Washington

Diana DiNitto

University of Texas at Austin

Bridget Freisthler

Ohio State University

Aruna Gogineni

Harbor Area Behavioral Health

James Hall

Indiana University

Michie Hesselbrock

University of Connecticut

Victor Hesselbrock

University of Connecticut

Lori Holleran Steiker

University of Texas at Austin

Amy Krentzman

University of Minnesota

Alexis Kuerbis

Hunter College

Marilyn Lewis

Norfolk State University
Barry Loneck

University at Albany

Hilda Loughran

University College Dublin

Barris Malcolm

University of Connecticut

Jennifer Manuel

New York University

Vivia McCutcheon

Washington University

Natasha Mendoza

Arizona State University

Laura Nissen

Portland State University

Margaret (Peggy) Murray

National Institute on Alcohol Abuse and Alcoholism

Thomas Nochajski

University at Buffalo

Stella Resko

Wayne State University

Danielle Ruderman

Ohio State University

Audrey Shillington

Colorado State University

Lala Straussner

New York University

Mary Velasquez

University of Texas at Austin

Eric Wagner

Florida International University 